\section{Case Reports in Neurology}

Case Rep Neurol 2020;12:410-415

DOI: $10.1159 / 000507242$

Published online: November 9, 2020

(c) 2020 The Author(s)

Published by S. Karger AG, Basel

www.karger.com/crn

This article is licensed under the Creative Commons Attribution-NonCommercial 4.0 International License (CC BY-NC) (http://www.karger.com/Services/OpenAccessLicense). Usage and distribution for commercial purposes requires written permission.

\title{
Dysphagia in a Young Man
}

\author{
Jing-Hwa Wey ${ }^{a, d} \quad J i n-E r L^{a} e^{b, d} \quad$ Kwang-Hwa Chang ${ }^{a, d, e}$ \\ Yen-Nung Lin ${ }^{a, d}$, e Wen-Kuei Chung ${ }^{a, c}, d$ \\ ${ }^{a}$ Department of Physical Medicine and Rehabilitation, Wanfang Hospital, Taipei Medical \\ University, Taipei, Taiwan; 'Department of Neurology, Wanfang Hospital, Taipei Medical \\ University, Taipei, Taiwan; 'Department of Neurosurgery, Wanfang Hospital, Taipei \\ Medical University, Taipei, Taiwan; ${ }^{\mathrm{d}}$ Taipei Neuroscience Institute, Taipei Medical \\ University, Taipei, Taiwan; ${ }^{e}$ Graduate Institute of Injury Prevention and Control, Taipei \\ Medical University, Taipei, Taiwan
}

\section{Keywords}

Dysphagia $\cdot$ Young adults $\cdot$ Meningitis $\cdot$ Rehabilitation

\begin{abstract}
This case report presents oropharyngeal dysphagia due to oromandibular and cervical dystonia, a rare consequence of aseptic meningitis. A 19-year-old male who was diagnosed with aseptic meningitis visited the rehabilitation outpatient clinic for a sense of foreign body in his throat and odynophagia. Repetitive involuntary movements of his facial, tongue, and laryngeal muscles accompanied by lateroanterior torticollis were observed. Videofluoroscopic swallowing study showed inefficient bolus formation due to repetitive rolling of his tongue and vallecular stasis without penetration or aspiration. Dysphagia and odynophagia had brought the patient significant weight loss and frustration. We provided swallowing training to improve the efficiency and safety of swallowing. The patient's symptoms improved gradually along with body weight gain and emotional stability. Acute-onset oropharyngeal dysphagia is devastating for young adults. A multidisciplinary approach is mandatory for optimal outcome. We share our experience as a team work and emphasize the rehabilitation aspect.
\end{abstract}

(C) 2020 The Author(s)

Published by S. Karger AG, Basel 


\section{Case Reports in Neurology}

Case Rep Neurol 2020;12:410-415

DOI: 10.1159/000507242

(c) 2020 The Author(s). Published by S. Karger AG, Basel www.karger.com/crn

Wey et al.: Dysphagia in a Young Man

\section{Introduction}

Oropharyngeal dysphagia is rare in young adults. Mostly, it is seen at extremes of age and caused by cerebral palsy, stroke, neurodegenerative disorders, and aging. Here, we present a case of oropharyngeal dysphagia caused by oromandibular and cervical dystonia secondary to aseptic meningitis in a 19-year-old male patient. Regardless of age group and etiology, dysphagia can lead to significant pulmonary, nutritional, and even psychological problems. The diagnosis is mainly based on clinical evaluations supported by studies including videofluoroscopic swallowing study, fiberoptic endoscopic evaluation of swallowing, and high-resolution manometry. A multidisciplinary approach with involvement of neurologists, physiatrists, psychiatrists, social workers, and speech-language pathologists is essential to achieve optimal treatment and improve the patient's quality of life.

\section{Case Report}

A 19-year-old male patient visited our emergency department due to severe right-sided headache and nausea without significant neurologic deficit. He was admitted to the neurology ward under the impression of intracranial insults. Bacterial culture and Indian ink stain for Cryptococcus were negative in cerebrospinal fluid. Therefore, acyclovir and ceftriaxone were discontinued 1 week later. Elevated microalbumin (88.57 mg/dL, normal range 10-30 mg/ $\mathrm{dL}$ ) and total protein (61.9 and $139.1 \mathrm{mg} / \mathrm{dL}$, normal range $15-45 \mathrm{mg} / \mathrm{dL}$ ) were detected in two series of cerebrospinal fluid studies with a 1-week interval. Serum vitamin B12 was relatively low (138 pg/mL, normal range 180-914 pg/mL). Electroencephalography did not detect cortical dysfunction. The results of magnetic resonance imaging and computed tomography studies were nonsignificant. He was discharged with a vitamin B12 supplement. One week after discharge, although headache had improved, he experienced neck stiffness and pain which later evolved with intermittent involuntary movement in his throat, mouth, and tongue as well as right lateroanterior torticollis (Fig. 1). The patient walked independently without device into the physical medicine and rehabilitation outpatient clinic 2 months after seeing several doctors for his discomfort. Upon examination, his neck was tilted to the right and forward with tight sternocleidomastoid, trapezius, splenius capitis, and levator scapulae muscles. Intermittent slow jaw opening and tongue protrusion with rapid up and down movement of both ears were noted. In neurologic examination, there were a positive Romberg test with abnormal tandem and a positive reverse tandem walk test. The finger-nose-finger test did not show dysmetria. Sitting and standing static and dynamic balance were good. The patient did not have difficulty in activities of daily living and had no difficulty in using chopsticks for taking meals. However, his social and occupational participation as a university student were interfered due to body image disfigurement. He was treated under the impression of oropharyngeal and cervical dystonia. The patient was referred back to a neurologist, but he had poor compliance to prescribed medications.

Therapeutic modalities including transcutaneous electrical nerve stimulation and hot packing did not improve his neck pain and tightness. He also complained of painful swallowing and engorgement in his throat, with occasional nausea when eating. Although he had no deterioration in articulation, phonation, or loudness, he could only speak in short sentences during intervals of dystonia remission. A significant reduction in body weight (10 kg) within 3 months was mentioned by the patient, and dry skin and lips were observed as signs of malnutrition and dehydration. For the swallowing difficulty, videofluoroscopic swallowing study 


\section{Case Reports in Neurology}

Case Rep Neurol 2020;12:410-415

DOI: $10.1159 / 000507242$

(c) 2020 The Author(s). Published by S. Karger AG, Basel www.karger.com/crn

Wey et al:: Dysphagia in a Young Man

revealed inefficient bolus formation due to repetitive tongue movement, premature leakage, and mild vallecula stasis without penetration or aspiration (Fig. 2). Our speech-language pathologist taught him safe swallowing techniques like repetitive swallowing and throat clearance, and compensatory swallowing technique like taking meals with thick consistency and food with no need for much chewing, and separated meals in decreased amount. Dystonia and its consequential symptoms improved spontaneously 6 months after onset since the patient did not take the prescribed medication. Fortunately, dysphagia-related aspiration pneumonia did not occur throughout the clinical course in this patient.

He was also referred to a psychiatrist due to lots of somatic complaints and anxious state. Since the criteria of depression, anxiety, or mania were not met, we referred this patient to a social worker for suggesting resources from his family, school, and community for emotional support. His anxious state was relieved along with clinical improvements. His doctor shopping also stopped since symptom relief. He then resumed his social and occupational activities as a university student.

\section{Discussion}

Oropharyngeal dysphagia is difficulty or discomfort in the oral preparatory, oral, and/or pharyngeal swallowing phases [1]. A thorough understanding of the disease's pathophysiology is essential to provide tailored treatment. In oropharyngeal dysphagia, functional disorders are more common than structural alteration, which is often the cause in esophageal dysphagia. Functional disorders are likely due to congenital, infectious or immunological, metabolic, or even iatrogenic disorders affecting the neuromuscular systems (central or peripheral nervous system or neuromuscular junction). Structural alterations that impair bolus progression are laryngoesophageal and neck tumors, neck osteophytes, postsurgical esophageal stenosis, and Zenker's diverticulum [2]. Acute infectious processes are more commonly seen in childhood through young adult dysphagia [3]. Although no obvious infectious source could be detected in our case, an inflammatory change in the nervous system was favored.

Dysfunctions led by oropharyngeal dysphagia are categorized into an inability or excessive delay in initiation of pharyngeal swallowing, aspiration of ingestate, nasopharyngeal regurgitation, and residue of ingestate within the pharyngeal cavity after swallowing [1]. Assessment tools to investigate the phase of dysphagia, presence of penetration, or aspiration can be direct or indirect visualization of the related anatomy during swallowing. Videofluoroscopic swallow study is a dynamic study for evaluating oropharyngeal swallowing anatomy and physiology and has been considered the study of choice for swallowing assessment. Other assessment tools for dysphagia include fiberoptic endoscopic evaluation of swallowing, which allows direct visualization of the related structures as well as bolus transit and airway protection, and high-resolution manometry, which investigates muscular function of the pharynx for upper esophageal sphincter during swallowing [2]. Mostly, complications of dysphagia include malnutrition, dehydration, aspiration, chest infection, and even death. Malnutrition leading to weight reduction can be a subtle change and often brings delayed attention and treatment. In the present case, repetitive involuntary contraction of facial, lingual, and neck muscles caused by cervical dystonia secondary to aseptic meningitis interfered with appropriate performance of swallowing and chewing and eventually led to weight loss and dehydration [4,5]. Videofluoroscopic swallow study was the assessment of choice to have good dynamic and indirect visualization of the related anatomy, and it was also easier for the patient to cooperate. 


\section{Case Reports in Neurology}

\begin{tabular}{l|l}
\hline Case Rep Neurol 2020;12:410-415 \\
\hline DOI: 10.1159/000507242 & $\begin{array}{l}\text { @ 2020 The Author(s). Published by S. Karger AG, Basel } \\
\text { www.karger.com/crn }\end{array}$ \\
\hline
\end{tabular}

Wey et al:: Dysphagia in a Young Man

The treatment for dysphagia is tailored according to the etiology of dysphagia along with swallowing therapy involving modification of either eating behavior or swallowing technique. Swallowing training included safe swallowing techniques like repetitive swallowing and throat clearance to reduce vallecular stasis and aspiration risk, and compensatory swallowing techniques like taking meals with thick consistency to reduce premature leakage, improve bolus formation, and taking a soft diet in small amount in separate meals to decrease muscle fatigue. Disturbance in psychosocial status and quality of life can be affected by oropharyngeal dysphagia and also cervical dystonia [6]. Due to disfigurement, patients frequently experience social embarrassment which results social phobia, depression, and anxiety. Reassurance and encouragement are essential for the patients and their caregivers to achieve good compliance and optimal treatment outcome.

\section{Conclusion}

We present a rare case of oropharyngeal dysphagia secondary to aseptic meningitis in a young adult. Detailed physical and laboratory examination together with image assessment can help us understand the etiology and mechanism of dysphagia. Tailored treatment in a multidisciplinary approach involving neurologists, physiatrists, speech-language pathologists, psychiatrists, and social workers is essential to achieve optimal outcomes, and let the patient go back to his premorbid functional status and have full participation in society.

\section{Acknowledgment}

We would like to acknowledge Prof. Winston W. Shen for emphasizing team collaboration in treating this patient and for English proofreading of the manuscript.

\section{Statement of Ethics}

The patient gave his written informed consent to publish images and personal medical records.

\section{Conflict of Interest Statement}

The authors have no conflicts of interest to declare.

\section{Funding Sources}

The authors received no funding. 


\section{Case Reports in Neurology}

\begin{tabular}{l|l}
\hline Case Rep Neurol 2020;12:410-415 \\
\hline DOI: 10.1159/000507242 & $\begin{array}{l}\text { @ 2020 The Author(s). Published by S. Karger AG, Basel } \\
\text { www.karger.com/crn }\end{array}$ \\
\hline
\end{tabular}

Wey et al.: Dysphagia in a Young Man

\section{Author Contributions}

Conception: W.-K. Chung, J.-H. Wey. Design: W.-K. Chung, J.-H. Wey. Supervision: K.-H. Chang, Y.-N. Lin. Materials: J.-E. Lee, J.-H. Wey. Data collection/analysis: J.-E. Lee, J.-H. Wey. Literature review: W.-K. Chung, J.-H. Wey. Writing: W.-K. Chung, J.-H. Wey. Critical review: W.-K. Chung, J.-H. Wey, J.-E. Lee.

\section{References}

1 Rommel N, Hamdy S. Oropharyngeal dysphagia: manifestations and diagnosis. Nat Rev Gastroenterol Hepatol. 2016 Jan;13(1):49-59.

2 Cook IJ, Kahrilas PJ. AGA technical review on management of oropharyngeal dysphagia. Gastroenterology. 1999 Feb;116(2):455-78.

3 Roden DF, Altman KW. Causes of dysphagia among different age groups: a systematic review of the literature. Otolaryngol Clin North Am. 2013 Dec;46(6):965-87.

4 Rofes L, Arreola V, Almirall J, Cabré M, Campins L, García-Peris P, et al. Diagnosis and management of oropharyngeal Dysphagia and its nutritional and respiratory complications in the elderly. Gastroenterol Res Pract. 2011;2011:818979.

5 Singer C, Papapetropoulos S. A comparison of jaw-closing and jaw-opening idiopathic oromandibular dystonia. Parkinsonism Relat Disord. 2006 Mar;12(2):115-8.

6 Zurowski M, McDonald WM, Fox S, Marsh L. Psychiatric comorbidities in dystonia: emerging concepts. Mov Disord. 2013 Jun;28(7):914-20.

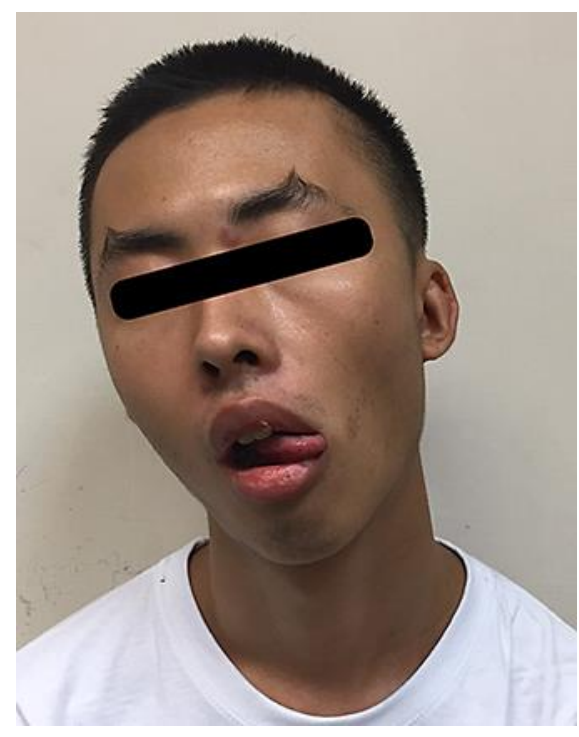

Fig. 1. Involuntary tongue protrusion and right-lateral torticollis. 
Case Reports in Neurology
Case Rep Neurol 2020;12:410-415

DOI: 10.1159/000507242

(c) 202 www

Wey et al:: Dysphagia in a Young Man

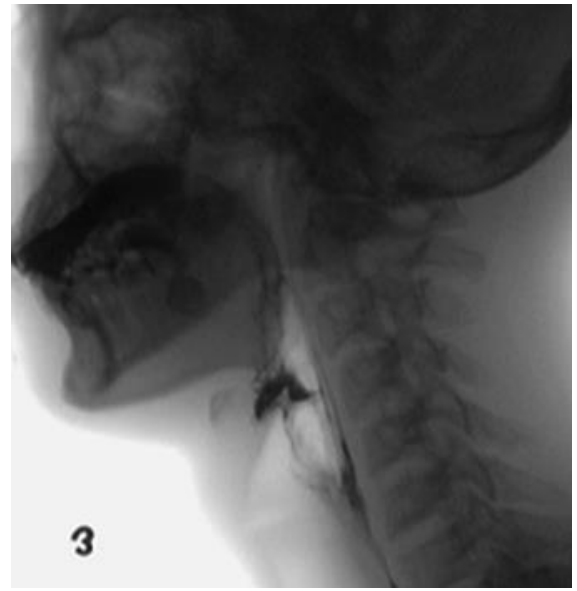

Fig. 2. Barium stasis in vallecula without penetration or aspiration. 